\title{
Anti-angiogenic activity of Middle East medicinal plants of the Lamiaceae family
}

\author{
QASEM ABDALLAH ${ }^{1}$, IBRAHIM Al-DEEB $^{2}$, AMMAR BADER $^{3}$, FAYEZ HAMAM $^{1}$, \\ KAMEL SALEH $^{4}$ and AMIN ABDULMAJID ${ }^{2}$
}

\begin{abstract}
${ }^{1}$ Department of Pharmacology and Toxicology, College of Pharmacy, Taif University, Taif, Makkah 21974, Saudi Arabia; ${ }^{2}$ Department of Pharmacology, School of Pharmaceutical Sciences, University Sains Malaysia, Minden, Penang 11800, Malaysia; ${ }^{3}$ Department of Pharmacognosy, College of Pharmacy, Umm Al-Qura University, Makkah 21955;

${ }^{4}$ Department of Biology, Science College, King Khalid University, Abha, Asir 61413, Saudi Arabia
\end{abstract}

Received May 15, 2018; Accepted June 11, 2018

DOI: $10.3892 / \mathrm{mmr} .2018 .9155$

\begin{abstract}
Angiogenesis plays a crucial role in malignant tumor progression and development. The present study aimed to identify lead plants with selective anti-angiogenic properties. A total of 26 methanolic extracts obtained from 18 plants growing in Saudi Arabia and Jordan that belong to the Lamiaceae family were screened for their cytotoxic and anti-angiogenic activities using MTT and rat aortic ring assays, respectively. Four novel extracts of Thymbra capitata (L.) Cav., Phlomis viscosa Poir, Salvia samuelssonii Rech.f., and Premna resinosa (Hochst.) Schauer were identified for their selective anti-angiogenic effects. These extracts did not exhibit cytotoxic effects on human endothelial cells (EA.hy926) indicating the involvement of indirect anti-angiogenic mechanisms. The active extracts are potential candidates for further phytochemical and mechanistic studies.
\end{abstract}

\section{Introduction}

The cure for cancer remains elusive notably for the majority of the solid malignancies. Various challenges in treating cancers are linked to tumor progression and metastasis $(1,2)$. The growth of solid malignances and their metastasis depends closely on adequate oxygen and nutrient supply, which ensures the formation of new blood vessels (angiogenesis) within the tumor that are vital for its growth (3). Therefore, anti-angiogenic agents may contribute in suppressing cancer growth by preventing nutrient and oxygen supply to the tumor. Plants have long been used as an important source of therapeutic

Correspondence to: Dr Qasem Abdallah, Department of Pharmacology and Toxicology, College of Pharmacy, Taif University, 2657 Airport Road, Taif, Makkah 21974, Saudi Arabia

E-mail: qasem79@yahoo.com

Key words: Salvia, Thymbra, Lamiaceae, angiogenesis, rat aortic assay, EA.hy926 cells agents against several diseases including cancer (4-8). While several natural products, such as taxanes and Vinca alkaloids are widely used in cancer treatment, the use of other plant products is limited to the support of the immune system and/or the increase in the anticancer effects of other anticancer drugs (4). The identification of plant extracts with anti-angiogenic activity and limited toxicity can potentiate the effects of currently used anticancer agents without increasing their side effects.

The targeting of tumor angiogenesis can be mediated via direct and indirect pathways $(9,10)$. Direct anti-angiogenic agents exhibit their effects by inhibiting the growth and migration of endothelial cells. The targeting of endothelial cells within tumors by such direct anti-angiogenic agents may result in unwanted side effects due to their toxicity on endothelial cells found in other tissues. Indirect anti-angiogenic agents inhibit the neovascularization within solid tumors by suppressing the expression of proangiogenic factors, such as vascular endothelial growth factor (VEGF) and platelet-derived growth factor (PDGF). The mechanism of indirect anti-angiogenic agents may also involve the growth inhibition of mural cells (pericytes) embedded within the vascular basement membrane of blood micro-vessels. This in turn leads to inhibition of the formation, stabilization, remodeling and function of blood vessels (11). Previous findings have shown the direct and indirect mechanisms of anti-angiogenic agents (11-13).

In the present study, we screened 26 methanolic extracts of plants belonging to the Lamiaceae family for their cytotoxic and anti-angiogenic effects. Their mechanism of action with regard to their selective anti-angiogenic properties was further explored by evaluating their ability to inhibit the growth and migration of human endothelial cells.

\section{Materials and methods}

Chemicals and materials. Chemicals were purchased from Sigma-Aldrich; Merck KGaA, (Darmstadt, Germany). Cell culture media and supplements were obtained from Gibco; Thermo Fisher Scientific, Inc., (Waltham, MA, USA) and all sterile plastics used in cell culture and experiments were 
obtained from Corning Incorporated, (Corning, NY, USA) unless specified otherwise.

Cell lines and cell culture conditions. The human colorectal adenocarcinoma cell lines (HT-29, Caco-2 and DLD-1) were a kind gift from Dr A. Aljada (Department of Basic Medical Sciences, College of Medicine, King Saud Bin Abdulaziz University for Health Sciences, Riyadh, KSA). The human endothelial cell line (EA.hy926) was obtained from the American Type Culture Collection (Manassas, VA, USA). The colorectal adenocarcinoma cell lines were routinely maintained in advanced RPMI-1640 medium (Reduced Serum Medium, cat no. 12633-012, Gibco, Life Technologies, Carlsbad, CA, USA) supplemented with $4 \mathrm{mM}$ L-glutamine, $4 \%$ fetal bovine serum (FBS) and $100 \mathrm{U} / \mathrm{ml}$ penicillin-streptomycin. EA.hy926 cells were routinely maintained in high glucose Dulbecco's modified Eagle's medium (DMEM) supplemented with $1 \mathrm{mM}$ sodium pyruvate, $2 \mathrm{mM}$ L-glutamine, $10 \% \mathrm{FBS}$ and $100 \mathrm{U} / \mathrm{ml}$ penicillin-streptomycin. All the cells were propagated in humidified atmosphere at $37^{\circ} \mathrm{C}$ supplemented with $5 \% \mathrm{CO}_{2}$.

Plant sample collection and extraction. A total of 18 plants belonging to the Lamiaceae family were collected from different locations in Saudi Arabia and Jordan and identified by analytical chemistry techniques. A voucher specimen of each plant was deposited to the Herbarium of Pharmacognosy Laboratory at the College of Pharmacy of the Umm Al-Qura University (Table I). The plants were air-dried in the shade at room temperature and then grinded finely. A total of $2 \mathrm{~g}$ of each plant were extracted with $20 \mathrm{ml}$ methanol under sonication for $8 \mathrm{~min}$ and kept for $24 \mathrm{~h}$ at room temperature prior to filtration. The filtrates were dried in glass petri dishes under ventilation. Finally, the crude extracts were dissolved in Dimethylsulfoxide (DMSO) in order to produce a solution with a final concentration of $200 \mu \mathrm{g} / \mathrm{ml}$. The extracts were kept at $-20^{\circ} \mathrm{C}$ until further use.

In vitro cytotoxic assay on colorectal cancer cells. HT-29 cells $(2,000$ cells/well) were seeded in 96-well plates and left to adhere overnight at $37^{\circ} \mathrm{C}$ in a humidified incubator with $5 \% \mathrm{CO}_{2}$. The cells were then exposed for $96 \mathrm{~h}$ to complete cell culture medium containing plant extracts $(100 \mu \mathrm{g} / \mathrm{ml})$. The final concentration of DMSO was $0.05 \%$ and each plate also contained blank wells, containing only medium and no cells, and control wells containing untreated cells. After the exposure time course, the MTT colorimetric assay was performed as previously described by Mosmann (14), with minor changes. Thus, the supernatant was replaced with $200 \mu \mathrm{l} /$ well of cell culture medium containing $0.5 \mu \mathrm{g} / \mathrm{ml}$ MTT and incubated for $4 \mathrm{~h}$. The insoluble formazan was dissolved by $150 \mu 1$ DMSO per well and the absorbance was measured at $540 \mathrm{~nm}$ (Spectramax ${ }^{\circledR}$ plus 384; Molecular Devices, LLC, Sunnyvale, CA, USA). The average absorbance in the control wells corresponded to $100 \%$ survival and the cell viability percentage following $100 \mu \mathrm{g} / \mathrm{ml}$ of the plant extract exposure was determined. All the extracts that induced $<50 \%$ growth inhibition at a concentration of $100 \mu \mathrm{g} / \mathrm{ml}$, were considered as non-cytotoxic and were selected for the direct anti-angiogenic screening.
Rat aortic ring assay. The procedure was performed as described by Brown et al (15), with minor modifications. Female Wistar rats (12-14 weeks old) were obtained from the animal house facility of the College of Pharmacy of Taif University. The rats were housed under standard animal facility conditions and were provided free access to food and water. The rats were maintained in a 12-h light/dark cycle at $25 \pm 2^{\circ} \mathrm{C}$ with relative humidity of $50-60 \%$. The in vivo protocol was in accordance with the animal welfare guidelines adopted by the Taif University and was approved by the Medical Ethics Committee of the Department of Pharmacology and Toxicology of the College of Pharmacy of Taif University. The rats were humanely euthanized by neck dislocation under anesthesia with ketamine/xylazine that was administered IP (70 $\mu \mathrm{g} / \mathrm{kg}$ ketamine and $10 \mu \mathrm{g} / \mathrm{ml}$ xylazine). The thoracic aorta was harvested, cleaned from fibro-adipose tissue and residual blood clots, and placed into M199 medium in order to maintain its integrity. The thoracic aorta was cut into rings of $1 \mathrm{~mm}$ in length and each ring/well was explanted into a 48-well plate preloaded with M199 medium (300 $\mu \mathrm{l} /$ well) containing fibrinogen $(3 \mu \mathrm{g} / \mathrm{ml})$ and aprotinin $(5 \mu \mathrm{g} / \mathrm{ml})$. In order to form the lower layer, $10 \mu \mathrm{l}$ of thrombin $(50 \mathrm{U} / \mathrm{ml}$ in normal saline: bovine serum albumin) was added and the layer was left to solidify for $1.5 \mathrm{~h}$ at $37^{\circ} \mathrm{C}$ in a $5 \% \mathrm{CO}_{2}$ supplemented humidified incubator. The upper layer M199 media (300 $\mu \mathrm{l} /$ well) consisted of $20 \%$ FBS, $2 \mathrm{mM} \mathrm{L-glutamine,}$ $0.1 \%(\mathrm{w} / \mathrm{v})$ aminocaproic acid and $1 \%$ penicillin streptomycin and amphotericin B antibiotics (Lonza Group, Ltd., Basel, Switzerland). The plant extracts were added to the top layer at a concentration of $100 \mu \mathrm{g} / \mathrm{ml}$, while suramine $100 \mu \mathrm{g} / \mathrm{ml}$ was used as a positive control. The concentration range of $50-25 \mu \mathrm{g} / \mathrm{ml}$ was used only for those extracts that inhibited the formation of the new vascularization at $100 \mu \mathrm{g} / \mathrm{ml}$ by $50 \%$ or more compared with the untreated control. The treatment of the extracts and the control samples was held in independent duplicates. Subsequently, the plates were restored into a humidified incubator $\left(37^{\circ} \mathrm{C}\right.$ supplemented with $\left.5 \% \mathrm{CO}_{2}\right)$ for seven days. On day four, the media of the upper layer were changed with M199 media containing similar treatments and concentrations. After the completion of the treatment course, the formation of micro-vessels was evaluated using phase contrast microscopy following the method developed by Nicosia et al (16). The measurement of the distance of the micro-vessel outgrowth was analyzed using the Image J $1.51 \mathrm{n}^{\circledR}$ software (National Institute of Health, Bethesda, MA, USA).

The percentages of inhibition of micro-vessel formation were compared with non-treated control samples and were presented as mean \pm standard deviation (SD). All the extracts that showed $50 \%$ or higher $(\geq 50 \%)$ inhibition of micro-vessel formation at $100 \mu \mathrm{g} / \mathrm{ml}$, were considered potentially active and were selected for further evaluation.

Scratch assay of endothelial EA.hy926 cells. This assay was used to evaluate the effectiveness of selected plant extracts to prevent the movement and growth of endothelial cells following induction of a scratch. The scratch was performed manually on a monolayer of cells as described by Liang et al (17). Subsequently, EA.hy 926 cells $\left(4 \times 10^{5}\right.$ cells) were seeded into a 6-well plate. The cells were incubated in a $5 \% \mathrm{CO}_{2}$ supplemented humidified incubator at $37^{\circ} \mathrm{C}$ for $48 \mathrm{~h}$ until they reached 
$90 \%$ confluency and/or higher. A straight line in the middle of the monolayer was scratched using a sterile $200 \mu$ l-pipette tip. The supernatant was discarded, and the monolayer was rinsed with PBS twice before the addition of extracts at concentrations of 100,50 or $25 \mu \mathrm{g} / \mathrm{ml}$ in DMEM (2 ml). The control cells were treated with DMSO (0.05\% in DMEM). A total of five images of different areas were taken for each scratch using an inverted light microscope at 12 and $24 \mathrm{~h}$ (Leica Microsystems $\mathrm{GmbH}$, Wetzlar, Germany). The magnification used was x 50 . The area of the scratch in each image was analyzed using ImageJ $1.51 \mathrm{n}$ (National Institute of Health, Bethesda) software. The resulted area of scratched monolayer at each time point was expressed as the percentage of inhibition of migration compared with the mean area of the scratch at $0 \mathrm{~h}$. All experiments were performed in independent triplicates and the results were expressed as mean \pm SD.

Growth inhibition assay on EA.hy926 cell line. EA.hy926 cells $\left(1.5 \times 10^{3}\right.$ cells/well) were seeded in a 96 -well plate and left to adhere overnight at $37^{\circ} \mathrm{C}$ in a humidified incubator with $5 \% \mathrm{CO}_{2}$. The cells were exposed to plant extracts at a different concentration range (200-12.5 $\mu \mathrm{g} / \mathrm{ml})$ for $96 \mathrm{~h}$. The final concentration of DMSO was $0.1 \%$ or less and each plate also included blank wells, which contained only medium and no cells and control wells, which contained untreated cells. Following the completion of the exposure time course, the MTT colorimetric assay was performed as described above. The average absorbance in the control wells was considered as $100 \%$ survival and the $\mathrm{IC}_{50}$ values were defined as the extract concentrations that inhibited the cell growth by $50 \%$ after $96 \mathrm{~h}$ exposure. The results were obtained from three independent experiments and expressed as mean \pm SD.

Statistical analysis. All data were analyzed using SPSS v.22.0 (IBM Corp., Armonk, NY, USA). The inhibition assay data were compared using one way ANOVA, and the significant differences were evaluated at a confidence interval of $95 \%$ and $\mathrm{P}<0.05$. In addition, the Tukey post hoc statistical test was employed in order to produce pairwise comparisons among treatments.

\section{Results}

Cytotoxic activity. In the present study, 26 extracts were obtained from 18 plants of the Lamiaceae family and were evaluated for their antiproliferative activities against HT-29 colorectal cancer cells (Table I). The antiproliferative activity test of the extracts was performed with the aim to exclude those extracts with potential cytotoxic effects. Therefore, extracts which caused $50 \%$ growth inhibition or higher at a concentration of $100 \mu \mathrm{g} / \mathrm{ml}$, were considered potentially cytotoxic. The non-cytotoxic effects of the selected 16 plant extracts were confirmed on two other colorectal cancer cell lines, and finally they were screened for their anti-angiogenic activity on rat aortic rings (Table I).

Antiangiogenetic activity. The extracts that caused higher than and/or equal to $50 \%$ inhibition in micro-vessel formation compared with untreated aortic rings were considered potentially antiangiogenic. The inhibition of micro-vessel formation in rat

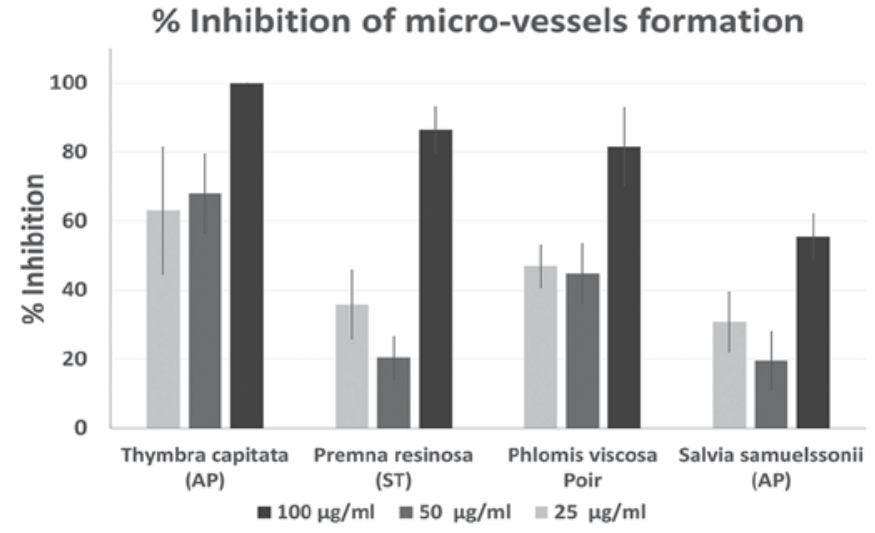

Figure 1. Percentage inhibition of micro-vessel formation in rat aortic ring assay is expressed as mean \pm SD following exposure to the extract at 100 , 50 and $25 \mu \mathrm{g} / \mathrm{ml}$. Percentage inhibition of micro-vessel formation in treated groups was calculated in comparison to corresponding untreated (negative) control. Inhibition was statistically significant compared to the control for all extracts at the concentrations tested $(\mathrm{P}<0.05)$. No significant differences were detected between percentage of inhibition for 25 and $50 \mu \mathrm{g} / \mathrm{ml}$ doses. AP, arial parts; ST, stems; SD, standard deviation.

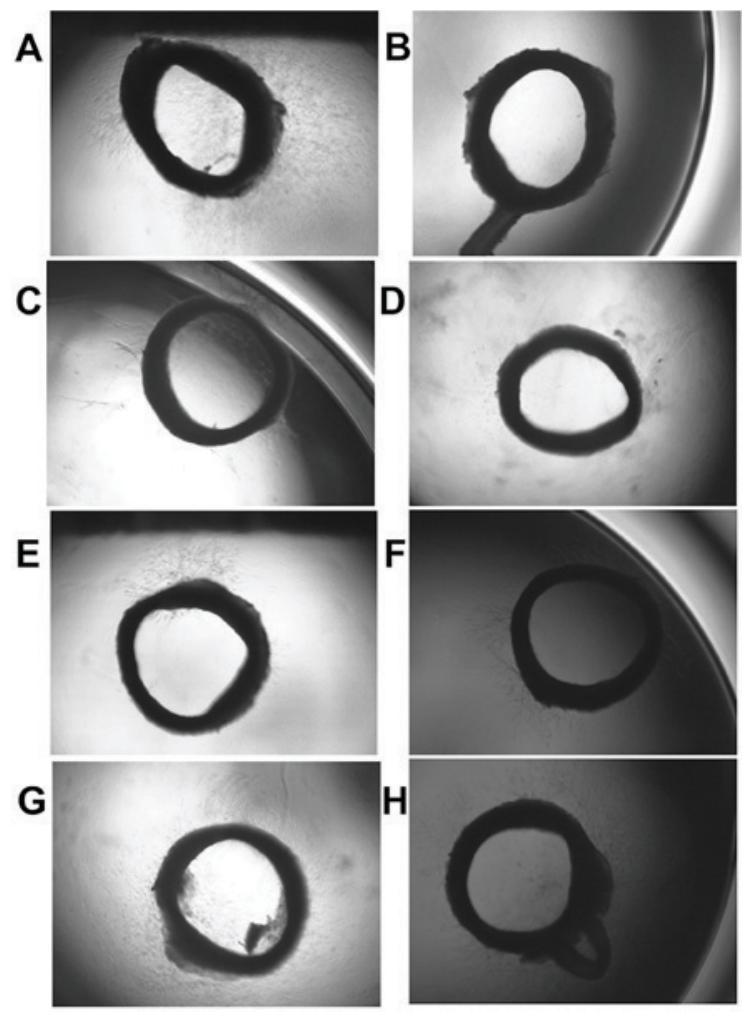

Figure 2. Effect of selected plant extracts on rat aortic ring assay (A) Negative control (0.05\% DMSO), (E) Positive control $(100 \mu \mathrm{g} / \mathrm{ml}$ Suramine), (B, C and D) 100, 50 and $25 \mu \mathrm{g} / \mathrm{ml}$ of Thymbra capitate (arial parts), (F) $100 \mu \mathrm{g} / \mathrm{ml}$ of Salvia samuelssonii (arial parts), (G) $100 \mu \mathrm{g} / \mathrm{ml}$ of Eremostachys laciniata, (H) $100 \mu \mathrm{g} / \mathrm{ml}$ of Moluccella laevis. DMSO, dimethylsulfoxide.

aortic rings was analyzed at a concentration of $100 \mu \mathrm{g} / \mathrm{ml}$ of extract (Table I). A total of six plants, namely Teucrium polium, Thymbra capitata, Phlomis viscosa Poir, Salvia samuelssonii, Salvia syriaca, and Premna resinosa were proven to have selective anti-angiogenic activity (Table I). These plants indicated no cytotoxic effects on cancer cells, although they significantly 


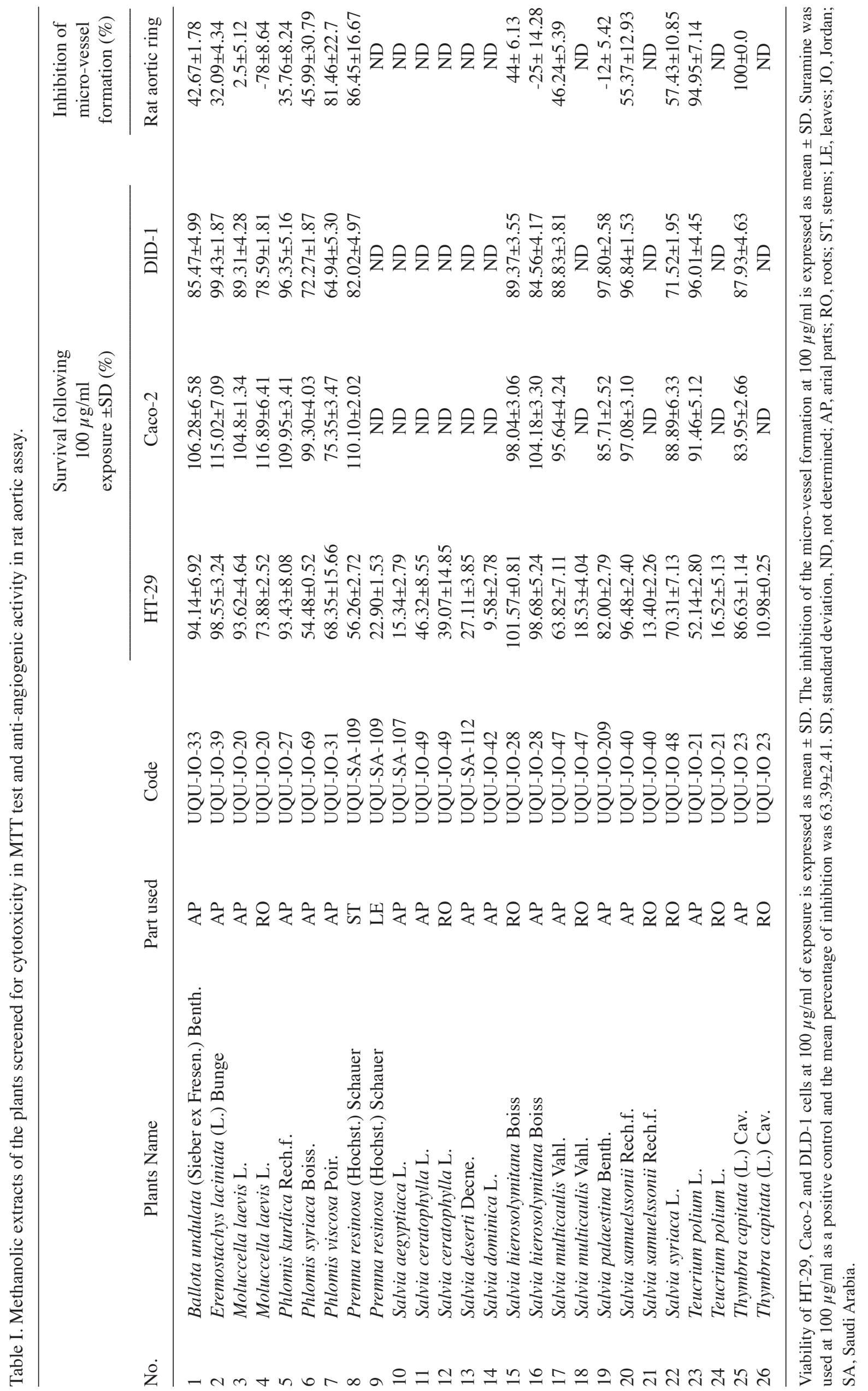




\section{Growth inhibition effect on EA.hy926 cells}
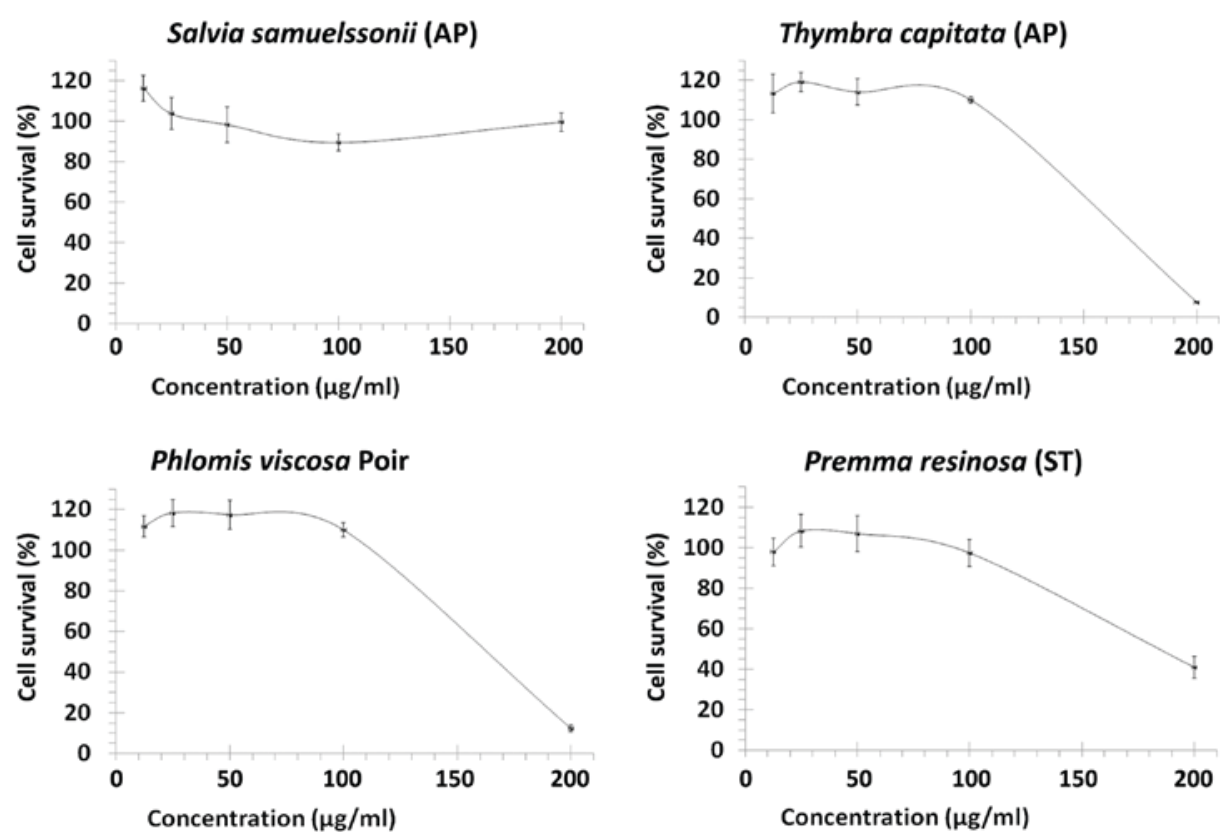

Figure 3. Growth inhibition assay on EA.hy 926 cells after $96 \mathrm{~h}$ exposure. $\mathrm{IC}_{50}$ values for Thymbra capitata, Phlomis viscosa Poir, Salvia samuelssonii and Premna resinosa were $158.70 \pm 12.12,161.42 \pm 10.91,>200$ and $184.14 \pm 8.2 \mu \mathrm{g} / \mathrm{ml}$ respectively. Negative control was $0.1 \%$ DMSO. The results are expressed as mean \pm SD of three independent experiments. AP, arial parts; ST, stems; DMSO, dimethylsulfoxide; SD, standard deviation.
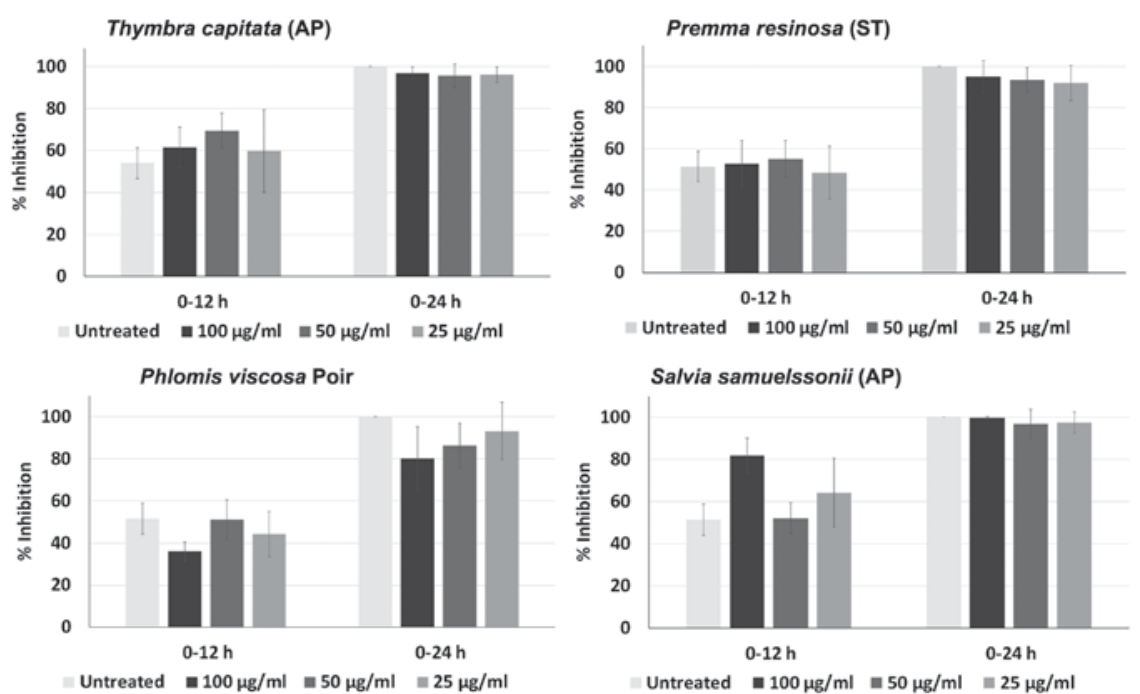

Figure 4. Percentage inhibition of scratch healing in endothelial EA.hy926 monolayer cell culture over $24 \mathrm{~h}$. Results were expressed as mean \pm SD of three independent experiments following incubation with the extracts at 100,50 and $25 \mu \mathrm{g} / \mathrm{ml}$. AP, arial parts; ST, stems; SD, standard deviation.

inhibited the formation of micro-vessels (Table I). The results of Teucrium polium and Salvia syriaca were in agreement with those demonstrated previously by Zihlif et al (18), with the exception of the Salvia syriaca, extract origin, which was derived from the roots, instead of the leaves. The remaining four plants were further investigated for their role in the inhibition of micro-vessel formation at lower concentrations (50 and $25 \mu \mathrm{g} / \mathrm{ml}$ ) as shown in Fig. 1 .

A significant drop in the percentage of inhibition was noted at lower concentrations, however no significant differences were observed among 50 and $25 \mu \mathrm{g} / \mathrm{ml}$. Furthermore, the highest efficacy was noted for Thymbra capitata. The repre- sentative images of the effect of the selected plant extracts on rat aortic vessel outgrowth are shown in Fig. 2.

Antiproliferative and anti-migratory activities of plant extracts on human endothelial cells (EA.hy926). The exposure of the endothelial EA.hy926 cells to the four selected plant extracts indicated no significant change in their growth rate (Fig. 3). Similarly, no significant effects were observed with regard to the endothelial proliferation and migration (Fig. 4). The latter results strongly indicated that these extracts did not mediate their anti-angiogenic effects via direct mechanisms of action. Selective anti-angiogenic assays on these crude extracts that 


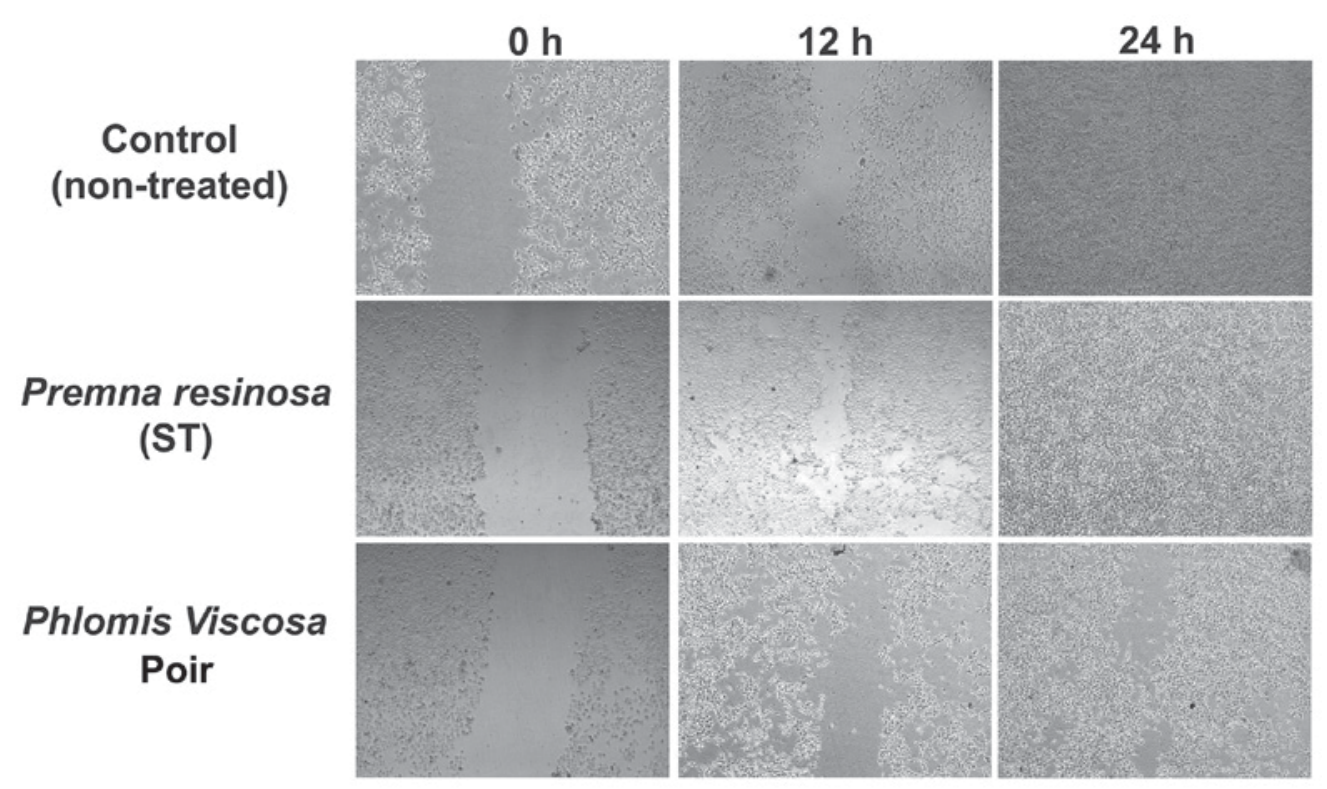

Figure 5. Scratch assay inhibition. A scratch was created and the cells were exposed to 100,50 and $25 \mu \mathrm{g} / \mathrm{ml}$ of plant methanolic extracts for $24 \mathrm{~h}$. Representative images captured in order to evaluate the effects of Premna resinosa and Phlomis viscosa Poir extracts on EA.hy926 endothelial cell proliferation and migration at 12 and $24 \mathrm{~h}$ using an inverted microscope at magnification, x50. The images were captured at 0,12 , and $24 \mathrm{~h}$. ST, stems.

can be conducted in future studies, can aid the evaluation of their therapeutic effects as complementary medicine and/or the isolation of their pharmacologically active ingredients.

\section{Discussion}

Tumor angiogenesis is linked to poor prognosis and metastasis (19). Co-administration of herbal medicines with anti-angiogenic properties as complementary treatment may enhance the therapeutic outcomes of anticancer therapy (20). Various Lamiaceae plants (e.g., Salvia and Phlomis species) have long been used in folk medicine for the treatment of various diseases including cancer $(5,21)$. For example, the diterpenoids isolated from the Lamiaceae plants demonstrated a wide range of pharmacological activities including antibacterial, antifungal, cytotoxic, cardiovascular and insecticidal activities. Salvia triloba (Lamiaceae) has demonstrated direct and indirect anti-angiogenic activities by inhibiting human umbilical vein endothelial cells (HUVECs) proliferation and expression of VEGF $(18,22)$. The AIS-L1023 extract from the leaves of Melissa officinalis (Lamiaceae) also inhibited tube formation of HUVECs by lowering the level of VEGF (23).

The micro-vessel formation assay in the aortic ring occurs by the proliferation and migration of endothelial cells, in addition to pericyte recruitment (24). Therefore, inhibition of angiogenesis in the cultured aortic rings could be mediated via direct and indirect mechanisms. The mechanism of action of the anti-angiogenic agents is mediated via direct and indirect pathways (25). The direct pathway involves the growth inhibition of endothelial cells via cytotoxic effects and/or via the inhibition of endothelial VEGF receptors. The indirect anti-angiogenic pathway, however, involves more complicated mechanisms and is active in the tissues surrounding the endothelial cells, thus leading to diminished expression of proangiogenic factors (26).
In conclusion, the present study identified several plants of the Lamiaceae family with potential selective anti-angiogenic activity. Their effects on angiogenesis were not mediated via a direct mechanism of action. Their activity could be attributed partially to the known compound carvacrol, which is the main constituent of the essential oil of Thymbra capitata (27). In addition, other constituents such as flavonoids could play a synergistic role in the anti-angiogenic activity of these extracts (28). With regard to the Salvia species, the diterpenes that are present in this extract have been reported to have anti-angiogenic effect, such as tanshinone, which is the main constituent of Salvia miltiorrhiza (29). Salvia samuelssonii could be a good target for further phytochemical studies as it has not been investigated with regard to its anti-angiogenic activity, with the exception of its essential oil, which has been characterized and includes phenylpropanoids, monoterpenes, sesquiterpenes and diterpenes (30). Phlomis viscosa is rich in bioactive compounds including oleanolic derivatives, iridoid glycosides, megastigmane, lignan glucosides, neolignan and phenylethanoid glycosides. The latter class of natural compounds includes verbascoside, isoacteoside, forsythoside B, myricoside, and samioside $(31,32)$. To the best of our knowledge, this is the first study that examined Phlomis species with regard to its anti-angiogenic effect. Premna resinosa is growing in Saudi Arabia and was recently investigated for its cytotoxic and antimicrobial activities (33). A previous study revealed the presence of several flavonoids with considerable bioactivity in this plant species (33). The extracts of Salvia hierosolymitana roots, Phlomis syriaca aerial parts and Salvia multicaulis aerial parts have been reported to have $50 \%$ of inhibition of micro-vessel formation. The activity of Salvia multicaulis was attributed to the presence of diterpenes and flavonoids $(34,35)$. The organs of the investigated plants have shown considerable differences in their activities, and this is attributed to the chemical diversity in the plant's organs. In some cases both aerial parts 
and roots have shown comparable effects, although they are phytochemically different, such as in the case of Salvia syriaca $(36,37)$. Further studies are warranted to explore the possible indirect pathway of their anti-angiogenic mechanism and to identify their active constituents.

\section{Acknowledgements}

Not applicable.

\section{Funding}

The present study was funded by the Taif University (grant no. 1-436-4303) (for anti-angiogenic assays) and by the National Plan for Science, Technology and Innovation (MAARIFAH) King Abdulaziz City for Science and Technology, Kingdom of Saudi Arabia, award number (12-MED2310-10) through Science and Technology Unit (STU) at Umm Al-Qura University (for cytotoxicity assays).

\section{Availability of data and materials}

The analyzed data sets generated during the study are available from the corresponding author on reasonable request.

\section{Authors' contributions}

QA planned, designed and conducted the present study. IA performed the cytotoxicity, rat aortic ring assay, scratch method and antiproliferative experiments. AM collected, identified and extracted the plants. KS and FH contributed in the scratch assay design and statistical analysis. AA contributed in rat aortic assay design, development and data analysis. All authors contributed to the scientific writing and the evaluation of the manuscript.

\section{Ethics approval and consent to participate}

The present study was approved by the Medical Ethics Committee at the Department of Pharmacology and Toxicology of the College of Pharmacy of Taif University.

\section{Patient consent for publication}

Not applicable.

\section{Competing interests}

The authors declare that they have no competing interests.

\section{References}

1. Folkman J: Tumor angiogenesis: Therapeutic implications. N Engl J Med 285: 1182-1186, 1971.

2. Carmeliet P and Jain RK: Angiogenesis in cancer and other diseases. Nature 407: 249-257, 2000.

3. Nishida N, Yano H, Nishida T, Kamura T and Kojiro M: Angiogenesis in cancer. Vasc Health Risk Manag 2: 213-219, 2006.

4. Shoeb M: Anti-cancer agents from medicinal plants. Bangladesh J Pharmacol 1: 35-41, 2006.

5. Balunas MJ and Kinghorn AD: Drug discovery from medicinal plants. Life Sci 78: 431-441, 2005.
6. Shaheen U, Ragab EA, Abdalla AN and Bader A: Triterpenoidal saponins from the fruits of Gleditsia caspica with proapoptotic properties. Phytochemistry 145: 168-178, 2018.

7. Bader A, Tuccinardi T, Granchi C, Martinelli A, Macchia M, Minutolo F, De Tommasi N and Braca A: Phenylpropanoids and flavonoids from Phlomis kurdica as inhibitors of human lactate dehydrogenase. Phytochemistry 116: 262-268, 2015.

8. Malafronte N, Vasallo A, Dal Piaz F, Bader A, Braca A and De Tommasi N: Biflavonoids from Daphne linearifolia Hart. Phytochem Lett 5: 621-625, 2012.

9. Kerbel R and Folkman J: Clinical translation of angiogenesis inhibitors. Nat Rev Cancer 2: 727-739, 2002.

10. Sogno I, Venè R, Ferrari N, De Censi A, Imperatori A, Noonan DM, Tosetti F and Albini A: Angioprevention with fenretinide: Targeting angiogenesis in prevention and therapeutic strategies. Crit Rev Oncol Hematol 75: 2-14, 2010.

11. Armulik A, Abramsson A and Betsholtz C: Endothelial/pericyte interactions. Circ Res 97: 512-523, 2005.

12. El-Kenawi AE and El-Remessy AB: Angiogenesis inhibitors in cancer therapy: Mechanistic perspective on classification and treatment rationales. Br J Pharmacol 170: 712-729, 2013.

13. Abdollahi A, Lipson KE, Sckell A, Zieher H, Klenke F, Poerschke D, Roth A, Han X, Krix M, Bischof M, et al: Combined therapy with direct and indirect angiogenesis inhibition results in enhanced anti-angiogenic and antitumor effects. Cancer Res 63: 8890-8898, 2003.

14. Mosmann T: Rapid colorimetric assay for cellular growth and survival: Application to proliferation and cytotoxicity assays. J Immunol Methods 65: 55-63, 1983.

15. Brown KJ, Maynes SF, Bezos A, Maguire DJ, Ford MD and Parish CR: A novel in vitro assay for human angiogenesis. Lab Invest 75: 539-555, 1996.

16. Nicosia RF, Lin YJ, Hazelton D and Qian X: Endogenous regulation of angiogenesis in the rat aorta model. Role of vascular endothelial growth factor. Am J Pathol 151: 1379-1386, 1997.

17. Liang CC, Park AY and Guan JL: In vitro scratch assay: A convenient and inexpensive method for analysis of cell migration in vitro. Nat Protoc 2: 329-333, 2007.

18. Zihlif M, Afifi F, Abu-Dahab R, Abdul Majid AM, Somrain H, Saleh MM, Nassar ZD and Naffa R: The anti-angiogenic activities of ethanolic crude extracts of four Salvia species. BMC Complement Altern Med 13: 358, 2013.

19. Kerbel RS: Tumor angiogenesis. N Engl J Med 358: 2039-2049, 2008.

20. Hurwitz H, Fehrenbacher L, Novotny W, Cartwright T, Hainsworth J, Heim W, Berlin J, Baron A, Griffing S, Holmgren E, et al: Bevacizumab plus irinotecan, fluorouracil, and leucovorin for metastatic colorectal cancer. N Engl J Med 350: 2335-2342, 2004.

21. Dal Piaz F, Vassallo A, Lepore L, Tosco A, Bader A and De Tommasi N: Sesterterpenes as tubulin tyrosine ligase inhibitors. First insight of structure-activity relationships and discovery of new lead. J Med Chem 52: 3814-3828, 2009.

22. Atmaca $\mathrm{H}$ and Bozkurt E: Apoptotic and anti-angiogenic effects of Salvia triloba extract in prostate cancer cell lines. Tumour Biol 37: 3639-3646, 2016.

23. Zihlif M, Afifi F, Muhtaseb R, Al-Khatib S, Abaza I and Naffa R: Screening the anti-angiogenic activity of medicinal plants grown and sold in Jordan. Planta Med 78: 297-301, 2012.

24. Baker M, Robinson SD, Lechertier T, Barber PR, Tavora B, D'Amico G, Jones DT, Vojnovic B and Hodivala-Dilke K: Use of the mouse aortic ring assay to study angiogenesis. Nat Protoc 7: 89-104, 2011.

25. Folkman J,Hahnfeldt P and Hlatky L: The logic of anti-angiogenic gene therapy. Vol. 36. Cold Spring Harbor Monograph Series, pp527-544, 1999 .

26. Yoshiji H, Harris SR and Thorgeirsson UP: Vascular endothelial growth factor is essential for initial but not continued in vivo growth of human breast carcinoma cells. Cancer Res 57: 3924-3928, 1997.

27. Başer KHC: Biological and pharmacological activities of carvacrol and carvacrol bearing essential oils. Curr Pharm Des 14: 3106-3119, 2008. (Review).

28. Adzet T and Martinez F: Flavonoids in the leaves of Thymus: A chemotaxonomic survey. Biochem Syst Ecol 9: 293-295, 1981.

29. Gong Y, Li Y, Lu Y, Li L, Abdolmaleky H, Blackburn GL and Zhou JR: Bioactive tanshinones in Salvia miltiorrhiza inhibit the growth of prostate cancer cells in vitro and in mice. Int $\mathbf{J}$ Cancer 129: 1042-1052, 2011. 
30. Bader A, Cioni PL, De Tommasi N and Flamini G: Essential oil compositions of two populations of Salvia samuelssonii growing in different biogeographical regions of Jordan. Nat Prod Commun 9: 141-143, 2014.

31. Çaliş I, Kirmizibekmez H, Taşdemir D and Rüedi P: Two new triterpene and a new nortriterpene glycosides from Phlomis viscose. Helv Chim Acta 87: 611-619, 2004.

32. Calis I, Kirmizibekmez H, Beutler JA, Dönmez AA, Yalçin FN, Ķiliç E, Özalp M, Rüedi P and Taşdemir D: Secondary metabolites of Phlomis viscosa and their biological activities. Turk J Chem 29: 71-81, 2005.

33. Albadawi DA, Mothana RA, Khaled JM, Ashour AE, Kumar A, Ahmad SF, Al-Said MS, Al-Rehaily AJ and Almusayeib NM: Antimicrobial, anticancer, and antioxidant compounds from Premna resinosa growing in Saudi Arabia. Pharm Biol 55: $1759-1766,2017$.

34. Ulubelen A, Topçu G and Johansson CB: Norditerpenoids and diterpenoids from Salvia multicaulis with antituberculous activity. J Nat Prod 60: 1275-1280, 1997.
35. Kharazian N: Chemotaxonomy and flavonoid diversity of Salvia L. (Lamiaceae) in Iran. Acta Bot Bras 28: 281-292, 2014.

36. Ulubelen A, Oksüz S, Kolak U, Birman H and Voelter W: Cardioactive terpenoids and a new rearranged diterpene from Salvia syriaca. Planta Med 66: 627-629, 2000.

37. Al-Jaber HI, Abrouni KK, Al-Qudah MA and Abu Zarga MH: New terpenes from Salvia palaestina Benth. and Salvia syriaca L. growing wild in Jordan. J Asian Nat Prod Res 14: 618-625, 2012

This work is licensed under a Creative Commons Attribution-NonCommercial-NoDerivatives 4.0 International (CC BY-NC-ND 4.0) License. 